\title{
Caftaric Acid Isolation from Unripe Grape: A "Green" Alternative for Hydroxycinnamic Acids Recovery
}

\author{
Veronica Vendramin ${ }^{1}$ (D), Alessia Viel ${ }^{1}$ and Simone Vincenzi ${ }^{1,2, *}$ \\ 1 Centre for Research in Viticulture and Enology (CIRVE), University of Padova, Viale XXVIII Aprile 14, \\ 31015 Conegliano (TV), Italy; veronica.vendramin@unipd.it (V.V.); alessia.viel@unipd.it (A.V.) \\ 2 Department of Agronomy, Food, Natural Resources, Animals and Environment (DAFNAE), \\ University of Padova, Viale dell'Università 16, 35020 Legnaro (PD), Italy \\ * Correspondence: simone.vincenzi@unipd.it; Tel.: +39-0438453711
}

check for updates

Citation: Vendramin, V.; Viel, A.; Vincenzi, S. Caftaric Acid Isolation from Unripe Grape: A “Green" Alternative for Hydroxycinnamic Acids Recovery. Molecules 2021, 26, 1148. https://doi.org/10.3390/ molecules 26041148

Academic Editor: Mirella Nardini

Received: 15 January 2021

Accepted: 11 February 2021

Published: 21 February 2021

Publisher's Note: MDPI stays neutral with regard to jurisdictional claims in published maps and institutional affiliations.

Copyright: (c) 2021 by the authors. Licensee MDPI, Basel, Switzerland. This article is an open access article distributed under the terms and conditions of the Creative Commons Attribution (CC BY) license (https:/ / creativecommons.org/licenses/by/ $4.0 /)$.

\begin{abstract}
Phenolic acids represent about one-third of the dietary phenols and are widespread in vegetable and fruits. Several plants belonging to both vegetables and medical herbs have been studied for their hydroxycinnamic acid content. Among them, Echinacea purpurea is preferentially used for caffeic acid-derivatives extraction. The wine industry is a source of by-products that are rich in phenolic compounds. This work demonstrates that unripe grape juice (verjuice) presents a simple high-pressure liquid chromatography (HPLC) profile for hydroxycinnamic acids (HCAs), with a great separation of the caffeic-derived acids and a low content of other phenolic compounds when compared to E. purpurea and other grape by-products. Here it is shown how this allows the recovery of pure hydroxycinnamic acids by a simple and fast method, fast protein liquid chromatography (FPLC). In addition, verjuice can be easily obtained by pressing grape berries and filtering, thus avoiding any extraction step as required for other vegetable sources. Overall, the proposed protocol could strongly reduce the engagement of solvent in industrial phenolic extraction.
\end{abstract}

Keywords: hydroxycinnamic acids; caftaric acid; verjuice; FPLC; unripe grape juice

\section{Introduction}

Phenolic acids constitute about one-third of the dietary phenols and are widespread in vegetable and fruits. Phenolic acids are divided into two subgroups, the hydroxybenzoic (HBAs) and hydroxycinnamic acids (HCAs). HBAs show a C6-C1 structure and include gallic, $p$-hydroxybenzoic, protocatechuic, vanillic, and syringic acids, while HCAs are characterized by an aromatic ring with three-carbon side chain (C6-C3) and are primarily represented by caffeic, ferulic, coumaric, and sinapic acids (Figure 1).

In the past years, HCAs gained attention because of their cosmetic application as anti-tyrosinase, anti-collagenase, and anti-hyaluronidase activity, apart from an interesting photo-protection action [1], and for their possible application as a food additive to prevent oxidation [2]. HCAs are key precursors of several more complex polyphenols, are structural components of the cell wall, are involved in the plant defense system, and act as signaling molecules [3]. In plants, the first HCA produced is the $p$-coumaric acid, which is obtained from phenylalanine or tyrosine. This is then transformed into caffeic acid by hydroxylation. Ferulic and synaptic acid derive from caffeic acid by methoxyl and hydroxyl substitution and, in the case of synaptic acid, from an additional methylation [1]. HCAs are found in several conjugated forms, including amides (conjugated with mono- or polyamines, amino acids, or peptides), esters (mainly esters of hydroxy acids, such as tartaric acid and sugar derivatives), and sugars. Cinnamate esters occur widely in higher plants, while the amides seem to be less present [4]. Caffeic acid (CA)-derivatives is a group of compounds derived from modification of caffeic acid by esterification with organic acids, such as quinic acid (i.e., chlorogenic acid, neochlorogenic acid), glucaric acid (caffeoylglucaric acid) [5], and more frequently with tartaric acid (i.e., chicoric acid [6], caftaric acid, and 
coutaric acid) [7]. To date, several plants have been studied for their CA-derivatives content, plants belonging to both vegetables and medical herbs, e.g., Echinacea purpurea [8], Cichorium intybus [9] and C. endivia [10], Lactuca virosa [11], Eupatorium perfoliatum [5], and Smallanthus sonchifolius [12]. Nevertheless, other potential sources are known, for example, CA-derivatives were discovered to be quite abundant in fruits and particularly in grape berries [13]. The wine industry is a source of by-products that can be exploited for the recovery of high value compounds. Pomace, lees, and canes have been well explored in the past [14-16] as polyphenols sources, while less attention was dedicated to other products, such as unripe grapes. Cluster thinning is a common practice used to avoid over-cropping in compliance with the production regulations and is deemed a way to accelerate ripening and increase the grape quality, even if this function is still being debated [17]. Several parameters, among others, the grape variety and the weather conditions, which affect the plant production, define the degree of thinning, which could achieve up to $50 \%$ of cluster reduction [18]. Two main forms of berries reduction are spread, namely cluster thinning, consisting of the elimination of several complete clusters, and berry thinning, which involves the removal of the tips of the clusters [19]. Additionally, thinning is encouraged from institutional organs in particular cases (called "green harvest"), i.e., for a great imbalance between supply and demand of the international market [20], as in the case of the pandemic disease COVID-19. The clusters (or their parts) are usually left on the ground, and it makes it difficult to have a clear panorama of the effective waste mass. An alternative use of unripe grapes is the production of verjuice, an acidic juice traditionally produced in the Mediterranean area, which is extracted from the mechanical pressing of unripe green grapes. Verjuice has been mainly studied for its physicochemical and sensory properties [21,22], while its bioactive compounds were just recently isolated [23,24]. In grape berries, HCAs are constituted by caffeic, coumaric, and ferulic acids and are present mainly in their ester forms, associated with tartaric acid giving caftaric (CFA), coutaric (CUA), and fertaric (FEA) acids, respectively [25]. HCAs' levels in the juice of different Vitis vinifera and $V$. labrusca varieties were recorded as very variable, namely 4339.9-1681.0 and 4154.5-786.7 $\mu \mathrm{g} / 100 \mathrm{~g}$ in the former and in the latter, respectively [26]. The authors identified a strong difference in CFA content depending on Vitis species and varieties, while the other HCAs showed different patterns of accumulation amongst varieties, evidencing a general independency of hydroxycinnamic acids metabolisms. Total hydroxycinnamates concentrate mainly in grape berries pulp, and it has been recorded to peak prior to véraison [27]. The successive reduction of HCAs concentration depends on the grapes volume increase and on the engagement of key precursors into the biosynthesis pathways of other phenolic compounds $[18,20]$. Furthermore, HCAs reduce further during grape juice processing and winemaking, as these compounds are promptly oxidized by endogenous tyrosinase when the grape berries are crushed. Instead, the harvest of green berries and their processing through crushing and maceration could implement HCAs content [24]. Therefore, unripe grape juice (verjuice) represents a rich source of hydroxycinnamic acids and should be considered as raw material for the HCAs extraction.

Several patents aiming to improve the recovery of CA-derivates from plants have been deposited in the past. Among them, the proposed raw material, E. purpurea adventitious roots, were recognized as the most suitable for the HCAs production at industrial scale because of their easy management and the high yield [28]. HCAs are extracted mainly in their ester form as chicoric (CCA), caftaric (CFA), and chlorogenic acids (CLA) [29]. Generally, these protocols involve the use of organic solvents, acidification, centrifugation, and the retrieval of final compounds by filtering or, more often, by separation with macroporous adsorption resin, which strongly improved the final HCAs purity, which could pass from $31 \%$ up to $72 \% w / v[28,30,31]$. Finally, the compounds are further concentrated by crystallization upon acidification of the extract and its cooling or by evaporation at high temperatures (about $90{ }^{\circ} \mathrm{C}$ ) that could, however, degrade HCAs. This last concentration step permits the achievement of purity values above $90 \% w / w[21,26]$. 
Hydroxybenzoic acids<smiles>[R]c1cc(C(=O)O)cc([R2])c1O</smiles>

$\mathrm{R}_{1}=-\mathrm{OH}, \mathrm{R}_{2}=-\mathrm{OH}$

$\mathrm{R}_{1}=-\mathrm{H}, \mathrm{R}_{2}=-\mathrm{H}$

$\mathrm{R}_{1}=-\mathrm{OH}, \mathrm{R}_{2}=-\mathrm{H}$

$\mathrm{R}_{1}=-\mathrm{OCH}_{3}, \mathrm{R}_{2}=-\mathrm{H}$

$\mathrm{R}_{1}=-\mathrm{OCH}_{3}, \mathrm{R}_{2}=-\mathrm{OCH}_{3}$ gallic acid

$p$-hydroxybenzoic acid

protocatechuic acid

vanillic acid

syringic acid<smiles>[R]c1cc(/C=C/C(=O)O)cc([R2])c1O</smiles>

$\mathrm{R}_{1}=-\mathrm{OH}, \mathrm{R}_{2}=-\mathrm{H}$

$\mathrm{R}_{1}=-\mathrm{OCH}_{3}, \mathrm{R}_{2}=-\mathrm{H} \quad$ ferulic acid

$\mathrm{R}_{1}=-\mathrm{H}, \mathrm{R}_{2}=-\mathrm{H} \quad$ coumaric acid

$\mathrm{R}_{1}=-\mathrm{OCH}_{3}, \mathrm{R}_{2}=-\mathrm{OCH}_{3}$ sinapic acid

CA-derivates: caftaric acid<smiles>O=C(/C=C/c1ccc(O)c(O)c1)OC(C(=O)O)C(O)C(=O)O</smiles>

Figure 1. Chemical structures of hydroxybenzoic and hydroxycinnamic acids and of caftaric acid.

To obtain pure compounds, due to the coexistence of different HCA in E. purpurea, an additional step of high-pressure liquid chromatography (HPLC) separation is necessary. Thus, those procedures led to the production of high volume of pollutants and the requirement of high-pressure liquid chromatography dramatically increase the process costs.

Cluster thinning is commonly applied in different wine production regions, and the unripe berries are today underutilized, so this work proposes a method to valorize unripe grape by their juice as source of HCAs, with a particular attention paid to caftaric acid, which is supposed to have several healthy functions [32]. Verjuice obtained by grape berries manual pressing of five varieties, both international and local, have been compared during four successive weeks between bunch closure and early véraison, revealing that, overall, the highest amount of HCAs is recorded in the premature varieties and at the bunch closure. Additionally, a low-environmental impact chromatographic method that permits the reduction of chemical waste by eliminating the several purification steps has been tuned to separate and recover high purity caftaric acid from verjuice.

\section{Results and Discussion}

\subsection{Caftaric Acid Concentration over Green Grape Berries Maturation}

First, for a complete overview of the potentiality of the unripe grape as a caftaric acid source, it was considered important to determine which varieties and which moment of ripeness optimized CFA recovery. Therefore, five varieties, three international and two of the most important Italian ones, have been monitored on CFA production from bunch closure to the early véraison (Table 1 ). 
Table 1. Yield, titratable acidity (TA), sugar content (SC), caftaric (CFA), and coutaric acid (CUA) concentration of verjuice obtained by different grape varieties during green berries maturation. Values represent the mean averages $(n=3)$ and standard deviation (in brackets).

\begin{tabular}{|c|c|c|c|c|c|c|c|c|}
\hline Variety & BBCH Code & Yield (\%) & TA $(g / L)^{1}$ & $\mathrm{SC}(\mathrm{g} / \mathrm{L})$ & CFA (mg/L) & CFA Purity $(\%)^{2}$ & CUA $(\mathrm{mg} / \mathrm{L})$ & CUA Purity $(\%)^{2}$ \\
\hline $\mathrm{CH}$ & 75 & $57.4(0.3)$ & $28.2(0.4)$ & $7.3(0.6)$ & $412.1(12.2)$ & $44.9(3.1)$ & $50.1(2.8)$ & $11.6(1.3)$ \\
\hline $\mathrm{CH}$ & 77 & $57.3(2.5)$ & $35.1(1.0)$ & $8.0(1.0)$ & $230.4(39.4)$ & $46.8(2.9)$ & $58.8(5.6)$ & $11.5(1.5)$ \\
\hline $\mathrm{CH}$ & 79 & $63.1(1.6)$ & $42.6(3.6)$ & $9.7(0.6)$ & $173.1(16.7)$ & $48.7(0.6)$ & $14.3(4.0)$ & $11.1(1.1)$ \\
\hline $\mathrm{CH}$ & 81 & $66.1(1.0)$ & $33.3(3.6)$ & 53. $7(16.0)$ & $257.5(25.7)$ & $47.3(3.4)$ & $70.5(4.0)$ & $11.42(1.3)$ \\
\hline GL & 73 & $50.8(1.1)$ & $32.6(1.3)$ & $9.0(0.1)$ & $295.8(7.6)$ & $61.2(3.0)$ & $23.5(9.3)$ & $8.0(0.2)$ \\
\hline GL & 75 & $46.0(0.7)$ & $41.8(0.7)$ & $11.7(0.6)$ & $272.5(19.6)$ & $67.6(2.8)$ & $50.2(10.5)$ & $6.36(1.4)$ \\
\hline GL & 77 & $52.5(0.9)$ & $40.5(0.7)$ & $11.7(0.6)$ & $165.1(1.4)$ & $62.4(7.0)$ & $36.6(7.7)$ & $7.6(0.5)$ \\
\hline GL & 79 & $55.1(0.3)$ & $39.5(0.9)$ & $27.0(2.7)$ & $179.8(5.8)$ & $63.3(1.0)$ & $23.0(2.0)$ & $7.3(0.2)$ \\
\hline $\mathrm{ME}$ & 75 & $54.7(2.8)$ & $29.6(0.6)$ & $8.3(0.6)$ & $207.0(40.4)$ & $52.4(0.9)$ & $54.2(8.8)$ & $7.2(0.2)$ \\
\hline $\mathrm{ME}$ & 77 & $59.7(0.9)$ & $38.4(0.1)$ & $10.0(0.1)$ & $296.1(34.1)$ & $50.9(4.1)$ & $18.5(7.6)$ & $8.2(0.2)$ \\
\hline $\mathrm{ME}$ & 79 & $62.3(1.3)$ & $42.5(0.7)$ & $11.0(1.0)$ & $222.8(20.3)$ & $58.3(6.6)$ & $28.1(7.3)$ & $6.2(0.8)$ \\
\hline $\mathrm{ME}$ & 81 & $64.9(1.6)$ & $34.8(2.6)$ & $36.3(5.9)$ & $154.0(13.1)$ & $48.7(6.9)$ & $36.5(9.1)$ & $7.5(0.9)$ \\
\hline $\mathrm{PN}$ & 77 & $52.1(2.3)$ & $27.80(0.6)$ & $7.0(0.1)$ & $161.6(15.9)$ & $59.8(3.4)$ & $13.3(2.0)$ & $8.9(0.6)$ \\
\hline $\mathrm{PN}$ & 79 & $56.7(1.4)$ & $38.9(0.1)$ & $7.7(0.6)$ & $211.1(6.3)$ & $58.4(9.7)$ & $47.2(5.5)$ & $11.7(2.1)$ \\
\hline $\mathrm{PN}$ & 81 & $58.3(2.8)$ & $45.7(0.2)$ & $21.0(0.1)$ & $267.4(33.5)$ & $63.0(1.4)$ & $21.9(2.2)$ & $8.2(0.5)$ \\
\hline $\mathrm{PN}$ & 83 & $60.7(1.6)$ & $35.8(1.0)$ & $43.7(3.1)$ & $192.9(10.8)$ & $57.8(4.8)$ & $22.6(6.1)$ & $8.1(0.6)$ \\
\hline SG & 73 & $55.2(2.2)$ & $32.4(1.1)$ & $7.0(0.1)$ & $119.6(17.6)$ & $59.7(4.9)$ & $30.5(7.4)$ & $16.3(1.5)$ \\
\hline SG & 75 & $57.1(3.0)$ & $36.5(0.5)$ & $8.0(0.1)$ & $118.9(11.0)$ & $56.3(6.5)$ & $15.5(5.2)$ & $13.6(0.4)$ \\
\hline SG & 77 & $56.3(2.4)$ & $38.3(0.1)$ & $11.3(0.6)$ & $182.6(30.8)$ & $59.8(1.7)$ & $33.3(3.1)$ & $12.7(0.1)$ \\
\hline SG & 79 & $60.7(3.2)$ & $33.7(1.5)$ & $36.3(4.0)$ & $212.4(0.5)$ & $50.8(6.6)$ & $21.3(2.8)$ & $12.6(1.7)$ \\
\hline
\end{tabular}

${ }^{1}$ Titratable acidity is expressed as Tartaric acid equivalents. ${ }^{2}$ Hydroxycinnamic acid purity is calculated as the ratio between acid peak area and the total of peaks area at $280 \mathrm{~nm}$.

Because caftaric acid concentration is affected by the berry volume increase during maturation, the concentration was adjusted by mass/juice yield and the CFA per kilo of fresh grapes weight (FW) was compared (Figure 2a). Analyses of variance performed on a linear model of the standardized CFA concentration data recognized significant effects of variety $(\mathrm{F}(4,52)=23.2, p>0.01)$ and date of sampling $(\mathrm{F}(3,52)=17.8, p>0.01)$, while color, as well as time request for maturation, did not statistically affect CFA content, differently from the data reported by Burin and colleagues at the grape technical maturation [26]. However, the interaction between the two main factors was statistically significant, and this suggests that different caftaric acid accumulation is observed depending on the grape variety. Indeed, Figure 2a highlights that not all the varieties were significantly affected by the week of sampling. Moreover, while in Pinot Noir (PN), CFA is strongly reduced between the first and the second week $(85 \mathrm{mg} / \mathrm{kg}$ in one week), in Merlot (ME), the major reduction was recorded later, between the second and the last week of sampling $30.17 \mathrm{mg} / \mathrm{kg}$ (Figure 2a). PN and Glera (GL) revealed the greatest caftaric acid accumulation among red and white varieties, respectively (achieving $412.10 \pm 12.28$ and $298.86 \pm 7.55 \mathrm{mg} / \mathrm{L}$ of CFA at the bunch closure). HCAs accumulation is influenced by grape light exposure [33], which is correlated with leaf surface, characters varying among varieties. Concerning CUA, the overall analyses of variance revealed a significant effect of the variety $\left.\left(\mathrm{F}_{4,52}\right)=15.745, p>0.01\right)$ and the sampling date $(\mathrm{F}(3,52)=3.007$, $p=0.04)$ and again the interaction of the two factors was significant. Figure $2 \mathrm{~b}$ shows that Sangiovese (SG) and Chardonnay $(\mathrm{CH})$ were the major producers of coutaric acid, particularly at the bunch closure, followed by PN. If the total amount of HCAs is considered, it results that the highest amount is accumulated at (or before) the bunch closure, in decreasing order in PN (achieving $241.70 \mathrm{mg} / \mathrm{kg})$, SG $(182.58 \mathrm{mg} / \mathrm{kg}), \mathrm{CH}(178.73 \mathrm{mg} / \mathrm{kg})$, 
GL (161.96 mg/kg), and ME (102.67 mg/kg). Maturation variables, i.e., acidity, juice yield, and sugar content (SC), were related to HCAs concentrations (standardized per $1 \mathrm{~kg} F W$ ) and revealed negative significant correlation of CFA with yield $(\mathrm{r}=-0.67, p>0.01, n=20)$ and SC $(r=-0.48, p=0.045, n=20)$, while no significant correlation was found for CUA. Interestingly, the correlation between CFA and CUA results in a positive, not significant, correlation $(\mathrm{r}=0.31, p=0.17, n=20)$.
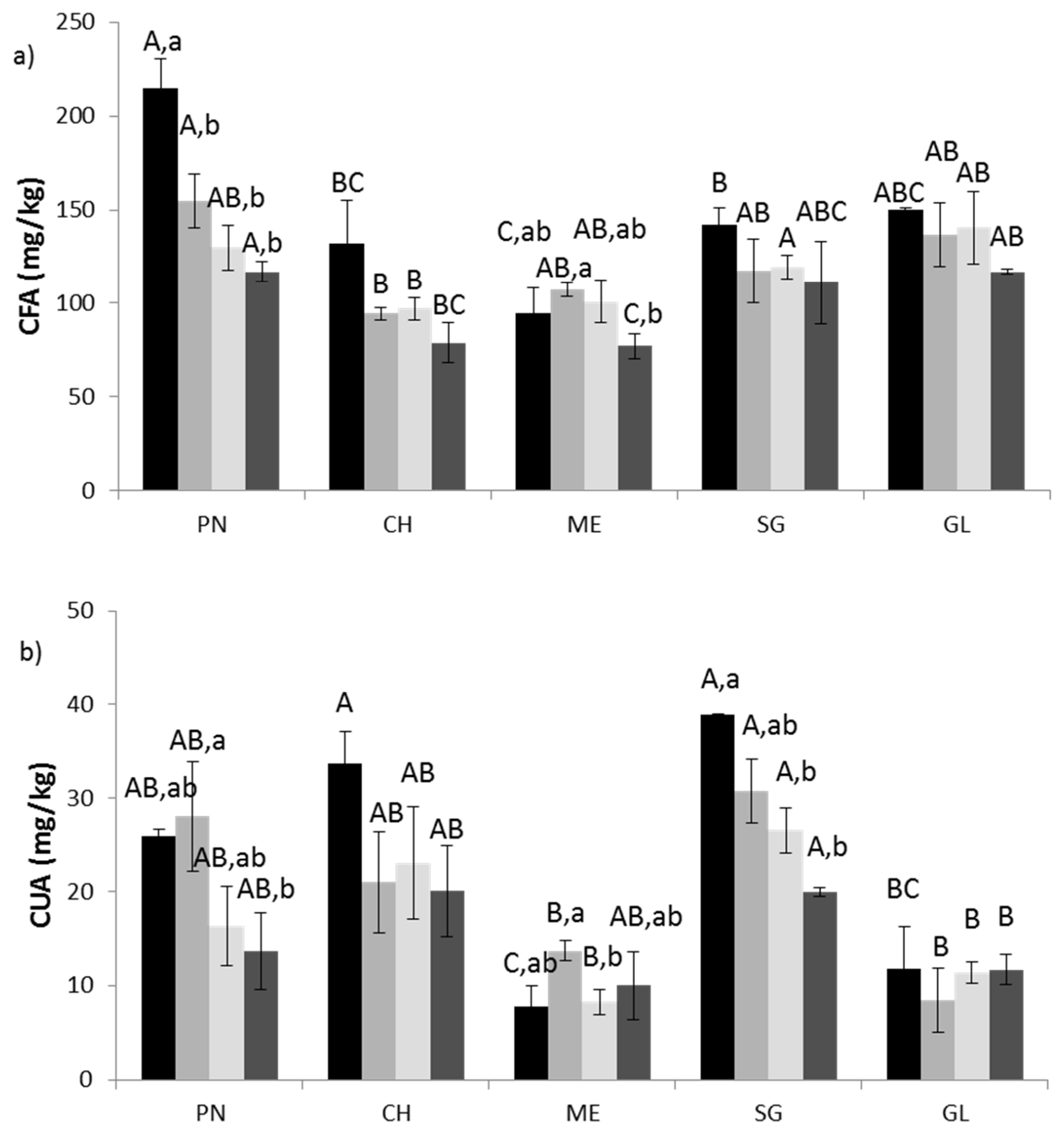

Figure 2. Standardized caftaric acid (a) and coutaric acid (b) content of verjuice. PN: Pinot noir, ME: Merlot, CH: Chardonnay, SG: Sangiovese, GL: Glera. Black bars: week one of sampling, grey bars: week two of sampling, light grey bars: week three of sampling, dark grey bars: week four of sampling. Different capital letter indicates significant differences among varieties at the same week of sampling; different lowercase letters indicates significant differences among weeks within the same variety. 


\subsection{Hydroxycinnamic Acid Esters in Verjuice}

The natural content in HCAs of unripe grape juice (verjuice) was analyzed using the HPLC method. All the analyzed verjuice revealed a simple peak profile for HCAs, with a great separation of the caffeic-derived acids and a general reduction of other phenolic compounds when compared with E. purpurea aerial part (Figure 3a,b). However, because of its availability, a verjuice obtained by pressing Riesling grapes collected in $2020 \mathrm{BBCH}$ stage 79) was used for purification. Two peaks were well distinguished. The first with a retention time (RT) of 8.54 min represented $74.1 \%$ of the total peak area, and a second peak at $\mathrm{RT}=9.82 \mathrm{~min}$ corresponded to $9.6 \%$ of the total area (Figure 3a).

a)

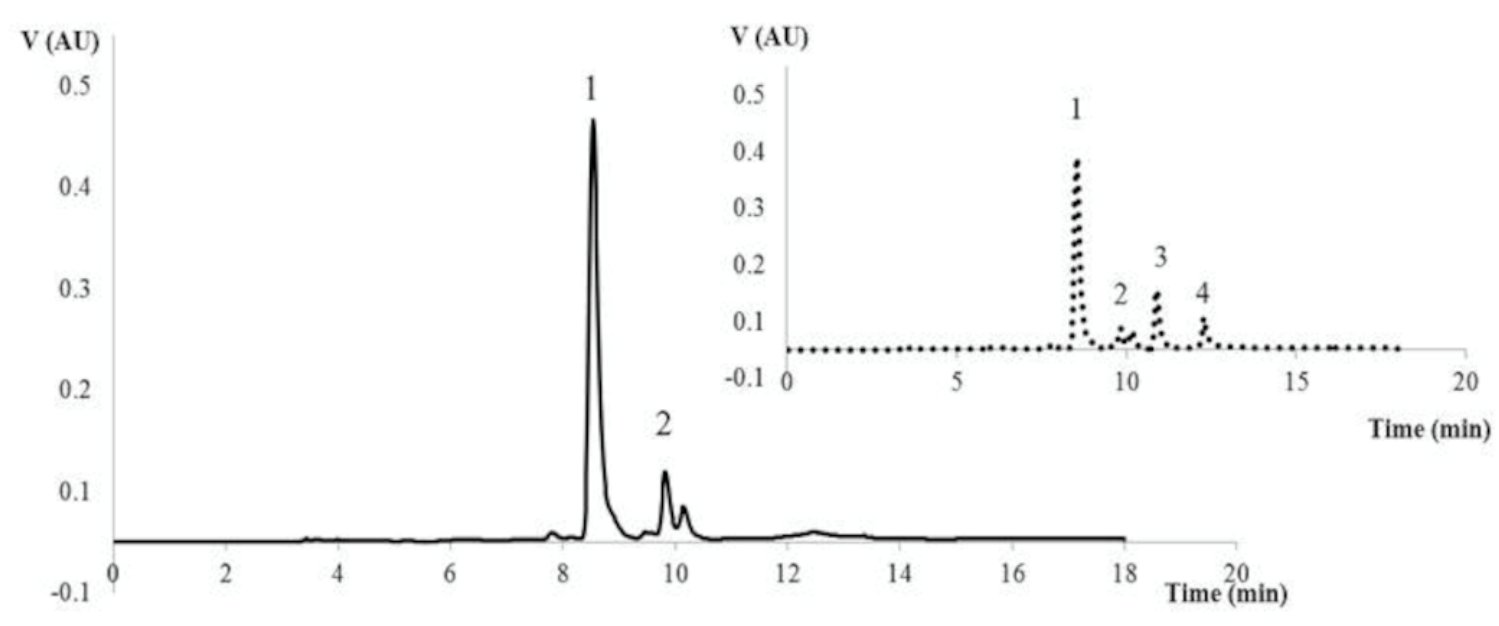

b)

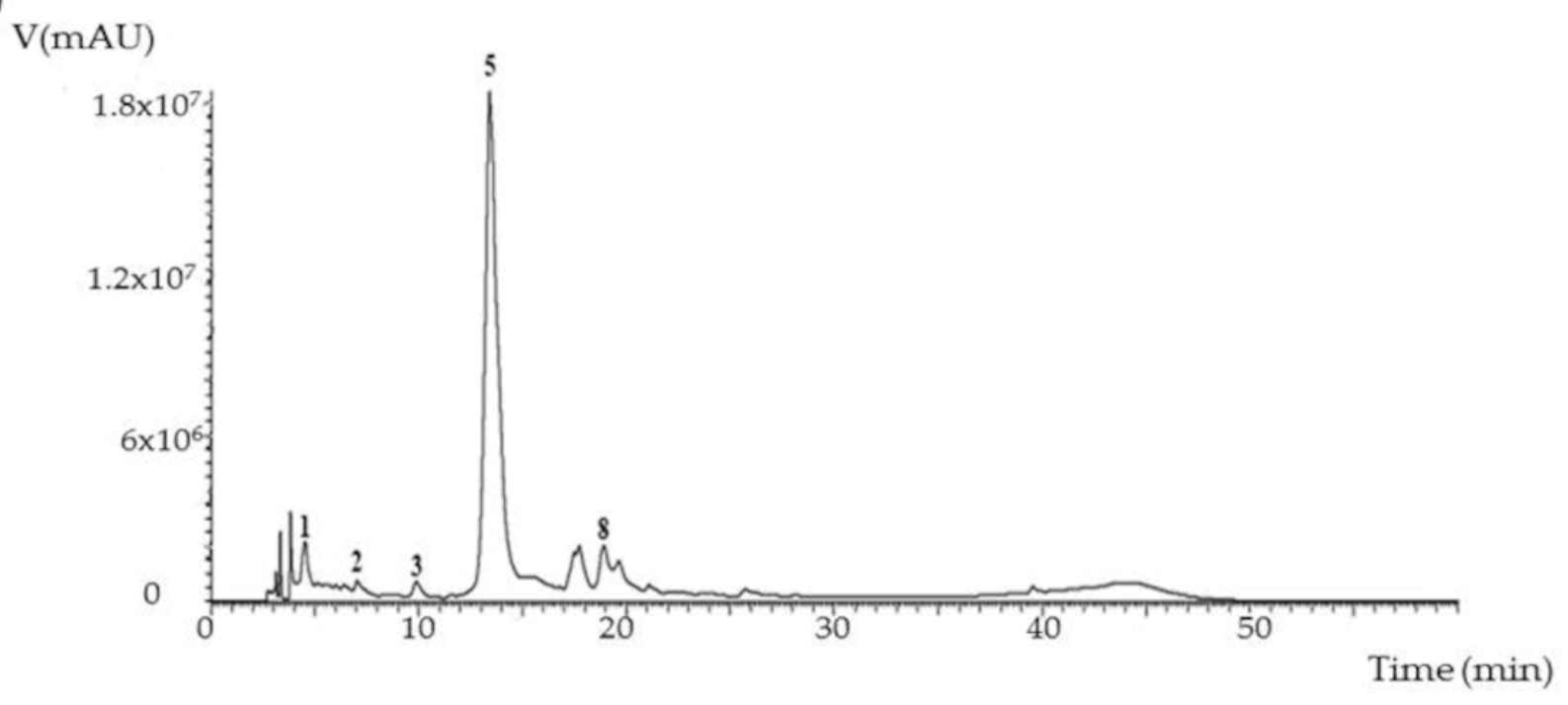

Figure 3. (a) HPLC profile of Riesling verjuice at $280 \mathrm{~nm}$, before (continuous line) and after (dashed line) enzymatic treatment obtained in this work. Peak 1: caftaric acid, peak 2: coutaric acid, peak 3: caffeic acid, peak 4: coumaric acid. (b) HPLC profile (at $280 \mathrm{~nm}$ ) of E. purpurea aerial part as reported by Coelho and colleagues [34]. Peak 1: caftaric acid, peak 2: 5-O-caffeoylquinic acid, peak 3: caffeic acid, peak 5: chicoric acid, peak 8: feruloylcaffeoyltartaric acid.

Peaks identification was performed using commercial standards (CFA, RT $=8.54 \mathrm{~min}$, caffeic acid, $\mathrm{RT}=11.0 \mathrm{~min}$, and coumaric acid, $\mathrm{RT}=12.4 \mathrm{~min}$ ), while coutaric acid (CUA), which is known to be the second hydroxycinnamic ester in grape for abundance [35], was identified by the comparison of HPLC profiles before and after an enzymatic degradation of ester bounds. The enzymatic reaction induced the appearance of two new peaks, corresponding to caffeic acid and coumaric acid. Additionally, the two original peaks 
were partially degraded, corresponding to the identified CFA peak and to the peak 2 (Figure 3a), which was consequently assigned to CUA. The analysis did not detect the fertaric acid that was probably present in too low concentration. The comparison between unripe grape juice and E. purpurea spectra made clear that while the latter is generally considered the best vegetable matrix for chicoric acid extraction, verjuice should be considered the best raw matrix for caftaric acid as well (Figure 3a,b). HCAs were quantified by the comparison of sample peaks area with a calibrating curve prepared using 25 to $200 \mathrm{mg} / \mathrm{L}$ of commercial CFA. Thus, CUA was expressed as CFA equivalents. Riesling grape juice contained $286 \mathrm{mg} / \mathrm{L}$ of caftaric acid and $38 \mathrm{mg} / \mathrm{L}$ of coutaric acid, namely about three times the maximum HCAs content detected in commercial verjuice [36]. This result could be explained in light of the strong effect of varieties and grape maturation point and because of the easy oxidation of HCAs during commercial verjuice preparation [37]. Considering the average yield of verjuice about $57 \% \mathrm{v} / \mathrm{m}$, the data could be easily transformed into 163.02 and $21.66 \mathrm{mg} / \mathrm{kg}$ of fresh grapes, respectively, not dissimilar from the data reported for grape pomace by Kammerer et al. [38]. In the work of Wu and colleagues [29], several conditions were tested in order to evaluate which ones optimize the CA-derivates extraction from E. purpurea roots. Authors reported that, growing the adventitious root at $20^{\circ} \mathrm{C}$ in an industrial system, $65 \mathrm{~g}$ fresh material could be obtained from $1 \mathrm{~L}$ of growth medium, corresponding to $10.4 \mathrm{~g}$ of dry material. The measured amount of caftaric acid was $4.9 \mathrm{mg} / \mathrm{g}$ of dry material corresponding to $784 \mathrm{mg}$ per kilo of fresh roots. Therefore, verjuice could represent a promising source of caftaric acid for its easy preparation that avoids the additional costs of a specific industrial plant.

\subsection{Fast Protein Liquid Chromatography Applied to Hydroxycinnamic Acid Esters Separation}

The most critical step in HCAs extraction from grapes raw material is represented by the isolation of the phenolic acids from other polyphenols. Chromatography was demonstrated to represent a handle tool for the selective isolation of HCAs ester in grape [39], and several methods have been tuned to obtain polyphenols high resolution peaks from fruits juice [40].

In addition to the traditional HPLC methods, Maier and colleagues [41] developed a method for CA-derivative esters recovery from ripe grape pomace based on the high-speed counter-current chromatography (HSCCC). This chromatography allowed the extraction and to successful separation of caffeic acid, coumaric acid, and ferulic acid esters by the head-to-tail elution mode, where the target compounds were separated from co-extracted polyphenolics and subsequently isolated in a second run. Liquid chromatography required a significantly longer time for separation; thus, CA-derivates separation required up to $390 \mathrm{~min}$ for the elution in the second HSCCC run. Additionally, this method involved the preliminary extraction with methanol and ethyl acetate and two mobile phases based on a mixture of hexane/ethyl acetate/methanol/water 3:7:3:7 $(v / v / v / v)$ and tertbutylmethyl ether/acetonitrile/n-butanol/water, 2:2:1:5 $(v / v / v / v)$, both acidified by $0.5 \%$ of trifluoroacetic acid (TFA), which represent high pollutant waste.

The simplicity of phenols profile of verjuice made possible a handy sample manipulation and the use of low-pressure chromatography as separation technology. Filtered juice of unripe berries has been processed without any sample preparation. After some preliminary tests, it has been determined that $50 \mathrm{~mL}$ of verjuice was the uploading limit for a column volume of $20 \mathrm{~mL}$. Nevertheless, this limit could be easily overtaken by rearranging the column sizes.

Separation was monitored by means of the UV detector (at $280 \mathrm{~nm}$ ). After sample loading, the column was washed with deionized water plus $0.5 \%$ trifluoroacetic acid (TFA) to remove the unanchored compounds, and then the target molecules were eluted by gradient of water: alcohol that achieves $30 \% v / v$ of alcohol in $100 \mathrm{~min}$.

Two commonly used solvent have been tested for the fast protein liquid chromatography (FPLC) separation, namely methanol, which is commonly used in HCAs chromatographic analyses [35], and ethanol, which was considered more suitable for further food 
application. The chromatographic profile revealed that well defined peaks could be obtained by methanol elution (Figure $4 a$ ), while ethanol elution evidenced less separation capability (Figure $4 b$ ).

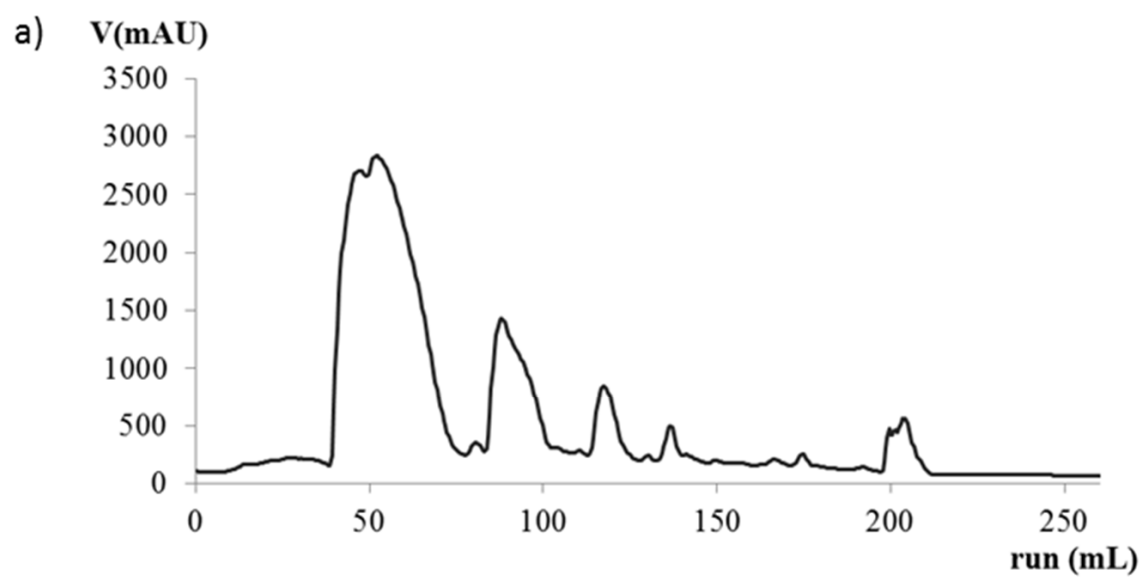

b) $\mathbf{V}(\mathbf{m A U})$

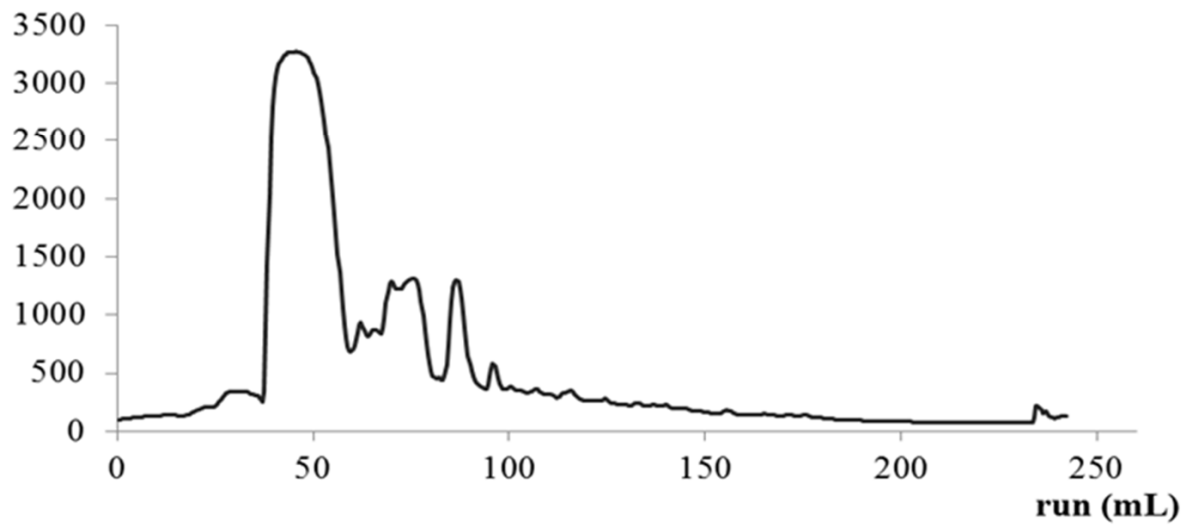

Figure 4. FPLCprofile of HCAs elution with (a) methanol and (b) ethanol as solvent.

Then, the methanol protocol was used in ten successive sample loadings, which obtained a repetitive elution profile. The first peak was assigned to CFA by HPLC analyses of its fractions. All the fractions that contained CFA at the minimal purity of $98 \%$ have been collected and freeze-dried. The final amount of crystallized CFA was $82 \mathrm{mg}$, which means a potential of $93.48 \mathrm{mg}$ of compound obtained from $1 \mathrm{~kg}$ of fresh grapes if a verjuice yield of $57 \% \mathrm{v} / \mathrm{m}$ is considered. As previously demonstrated [41], high-speed counter-current chromatography (HSCCC) leads to the recovery of high pure CA-derivates, i.e., $97.0 \%$ for CFA, $97.2 \%$ CUA, and $90.4 \%$ for fertaric acid. The method here proposed achieves similar results in terms of CFA purity with a strong reduction of solvents and time; indeed, the HSCCC method permitted the isolation and recovery of $6 \mathrm{mg}$ of caftaric acid, from $10 \mathrm{~g}$ of freeze-dried pomace, after a preliminary extraction that required $800 \mathrm{~mL}$ of methanol $/ 0.1 \%$ $\mathrm{HCl} v / v$ and $400 \mathrm{~mL}$ of ethyl acetate followed by the compounds separation in about $120 \mathrm{~mL}$ of hexane/ethyl acetate/methanol/water 3:7:3:7 v/v/v/v/ 0.5\% TFA plus $40 \mathrm{~mL}$ of ether/acetonitrile/n-butanol/water, 2:2:1:5, v/v/v/v/ 0.5\% TFA, while in this new method, $8.2 \mathrm{mg}$ of caftaric acid is obtained by the direct separation of $50 \mathrm{~mL}$ of verjuice in $70 \mathrm{~mL}$ of methanol 1:6 v/v/ 0.1\% TFA.

\section{Materials and Methods}

\subsection{Materials and Sample Preparation}

Unripe grapes of five varieties, namely Pinot Noir (PN), Chardonnay $(\mathrm{CH})$, Merlot (ME), Sangiovese (SG), and Glera (GL), were collected in the experimental vineyard of 
"Scuola Enologica di Conegliano G.B. Cerletti" (Treviso, Italy) in four successive weeks of 2019, between stage 73 and 83 of the BBCH scale. Samples were promptly added with 0.2 $\mathrm{g} / \mathrm{kg}$ of potassium metabisulphite and processed in a basket press. The obtained juice was centrifuged at $2000 \times g$ for $5 \mathrm{~min}$, then vacuum filtered through $1.6 \mu \mathrm{m}$ glass fiber filters (VWR, Milan, Italy) and kept frozen until HPLC analyses.

Additionally, unripe grape juice obtained from Rhine Riesling harvested at the véraison stage in 2020 was used for hydroxycinnamic acids recovery. Grape clusters were destemmed and washed before pressing with a small-scale stainless steel basket press. The basket press was loaded with berries in presence of $0.2 \mathrm{~g} / \mathrm{kg}$ of potassium metabisulphite. The juice was centrifuged and filtered as described above and used for HPLC analyses and FPLC immediately. All reagents were analytical grade and were purchased from Sigma (Milan, Italy) unless otherwise stated. Chromatographic identification and quantification of caffeic acid, coumaric acid, and caftaric acid (CFA) were performed by the comparison of Riesling verjuice peaks with their commercial standard, while coutaric acid (CUA) was identified after juice enzymatic treatment. CFA standard curve was used for the quantification. The enzymatic treatment was performed using a commercial pectolytic enzyme with cinnamoyl esterase secondary activity. Verjuice $(10 \mathrm{~mL})$ was treated with $10 \mathrm{~g} / \mathrm{hL}$ of enzyme and kept for $30 \mathrm{~min}$ at room temperature $\left(25^{\circ} \mathrm{C}\right)$ until the end of the reaction. Then, the sample was treated as described above before the injection.

\subsection{Grape Degree of Maturation Parameters}

Verjuice was immediately characterized by sugar content (SC) and total acidity (TA). Sugars were enzymatically determinaed by Hyperlab automatic multi-parametric analyzer (Steroglass, Perugia, Italy) by means of enzymatic kits, while titratable acidity was measured according to the official methods of wine analysis (Commission Regulation (EC) No1293/2005 of 5 August 2005 amending Regulation (EEC) No2676/90 determining Community methods for the analysis of wines).

\subsection{HCAs Determination in High Performance Liquid Chromatography (HPLC)}

Hydroxycinnamic acids (HCAs) separation was performed by C18 Lichrospher $(4 \times 250 \mathrm{~mm}, 5 \mu \mathrm{m}$, Agilent Technologies Italia, Milan, Italy) using a 1525 Binary Pump (Waters, Milan, Italy) equipped with 2487 Dual Band Absorbance Detector (Waters, Milan, Italy). Freshly prepared verjuice was centrifuged and filtered $(0.2 \mu \mathrm{m})$, then it was injected $(10 \mu \mathrm{L})$ and analyzed using the method proposed by Vanzo and colleagues [42] with modifications. Mobile phase was kept as proposed by the authors, while the flow rate was raised to $0.6 \mathrm{~mL} / \mathrm{min}$ and the gradient was modified as follows: (A) Milli-Q water and $0.5 \%$ of formic acid $v / v$ and (B) gradient-grade methanol and $2.0 \%$ of formic acid $v / v$. The gradient program was $0 \mathrm{~min}, 16 \% \mathrm{~B} ; 7 \mathrm{~min}, 50 \% \mathrm{~B} ; 8 \mathrm{~min}, 100 \% \mathrm{~B} ; 8-12 \mathrm{~min}, 100 \% \mathrm{~B} ; 13 \mathrm{~min}, 18 \%$ $\mathrm{B}$; and $13-18 \mathrm{~min}, 18 \% \mathrm{~B}$. The column temperature was kept at $40{ }^{\circ} \mathrm{C}$. Hydroxycinnamic acids and esters were detected at the wavelength of $280 \mathrm{~nm}$ for purity determination and $330 \mathrm{~nm}$ for HCAs quantification; the peak areas were analyzed by software Breeze Version 3.3 (Waters, Milan, Italy).

\subsection{HCAs Retrieve by Fast Protein Liquid Chromatography (FPLC)}

Filtered Riesling verjuice $(50 \mathrm{~mL})$ was loaded onto a Bio Scale Column MT20 $(15 \times 113 \mathrm{~mm}$, internal volume $20 \mathrm{~mL}$, Bio-Rad Laboratories, Milan, Italy) packed with LiChrosorb RP-18 (Sigma-Aldrich, Milan, Italy) and connected to an FPLC (AKTA purifier 10). The column was previously equilibrated with deionized water with $0.1 \%$ trifluoroacetic acid (TFA) and, after the sample loading, the column was washed with the same buffer to remove unbound sample components. The target compounds were eluted with a gradient of methanol $0.1 \%$ TFA, which linearly achieved $30 \%$ in $100 \mathrm{~min}$ with a flow rate of $2 \mathrm{~mL} / \mathrm{min}$. Fractions of $3.5 \mathrm{~mL}$ were collected by means of a fraction collector. The elution was monitored by recording the signal at $280 \mathrm{~nm}$, and the purity was checked by HPLC 
analysis. Fractions containing at least $98 \%$ of CFA were pooled together and freeze-dried by Heto cooling trap (Analitica De Mori, Milan, Italy).

\subsection{Statistical Analyses}

$\mathrm{R}$ software ( $\mathrm{R}$ version 3.0.1) was used for statistical analysis. Differences were evaluated by one-way ANOVA and the Games-Howell post-hoc analyses. Variable relationships were tested using Pearson correlation. Statistical significance was attributed with $p$-value $<0.05$.

\section{Conclusions}

Hydroxycinnamic acids and their derived ester gained new attention recently in light of their potential application as antioxidants and as bioactive molecules in food and cosmetic formulations.

Nowadays, hydroxycinnamic acids are mainly extracted form Echinacea purpurea roots, which are cultivated in an industrial plant set up with airlift bioreactors and require strictly controlled conditions of light, temperature, and nutrient availability, conditions that determine high cost of management. Nevertheless, other vegetables and herbs represent rich sources of HCAs and among them, grape berries.

In general, the extraction of HCAs from grapes' raw material, such as grape pomaces, faces the main problem of HCAs isolation from other phenolic compounds. On the other hand, verjuice polyphenols consist of a major part of hydroxycinnamic acids. This allows the reduction of costs and time for extraction and separation; the method here proposed demonstrates that a low-pressure separation procedure using fast protein liquid chromatography (FLPC) can be easily used to obtain high purity caftaric acid.

This work proposes the unripe grape juice as a new source of hydroxycinnamic acids, mainly represented by caftaric acid. This new approach gives two important technological advantages: the valorization of vineyard by-product in place of the installation of industrial plant for specific raw material production and the possibility of a more handy isolation of the target molecules. It should be underlined that this solution meets the general requirements of a new low-environmental impact alternative toward the reduction of solvents and the simplification of pure molecule recovery.

Author Contributions: Conceptualization: A.V. and S.V.; methodology: A.V. and S.V.; formal analysis: A.V. and V.V.; investigation: V.V.; resources: V.V. and S.V.; data curation: V.V.; writing-original draft preparation: V.V.; writing-review and editing: A.V. and S.V.; supervision: S.V.; funding acquisition: S.V. All authors have read and agreed to the published version of the manuscript.

Funding: This research received no external funding.

Informed Consent Statement: Not applicable.

Data Availability Statement: The data presented in this study are openly available in [repository name e.g., FigShare] at [doi], reference number [reference number].

Conflicts of Interest: The authors declare no conflict of interest.

\section{References}

1. Taofiq, O.; González-Paramás, A.M.; Barreiro, M.F.; Ferreira, I.C.F.R.; McPhee, D.J. Hydroxycinnamic acids and their derivatives: Cosmeceutical significance, challenges and future perspectives, a review. Molecules 2017, 22, 281. [CrossRef] [PubMed]

2. Yuan, Y.; Jiang, L. Application of Chicoric Acid Extract in Echinacea Purpurea. CN102726550, 17 October 2012.

3. Marchiosi, R.; dos Santos, W.D.; Constantin, R.P.; de Lima, R.B.; Soares, A.R.; Finger-Teixeira, A.; Mota, T.R.; de Oliveira, D.M.; de Pavia Foletto-Felipe, M.; Abrahão, J.; et al. Biosynthesis and metabolic actions of simple phenolic acids in plants. Phytochem. Rev. 2020, 19, 865-906. [CrossRef]

4. Teixeira, J.; Gaspar, A.; Garrido, E.M.; Garrido, J.; Borges, F. Hydroxycinnamic acid antioxidants: An electrochemical overview. BioMed Res. Int. 2013, 2013, 251754. [CrossRef] [PubMed]

5. Maas, M.; Petereit, F.; Hensel, A. Caffeic acid derivatives from Eupatorium perfoliatum L. Molecules 2009, 14, 36-45. [CrossRef] [PubMed]

6. Lee, J.; Scagel, C.F. Chicoric acid: Chemistry, distribution, and production. Front. Chem. 2013, 1, 40. [CrossRef] 
7. Lima, A.; Oliveira, C.; Santos, C.; Campos, F.M.; Couto, J.A. Phenolic composition of monovarietal red wines regarding volatile phenols and its precursors. Eur. Food Res. Technol. 2018, 244, 1985-1994. [CrossRef]

8. Lin, S.D.; Sung, J.M.; Chen, C.L. Effect of drying and storage conditions on caffeic acid derivatives and total phenolics of Echinacea purpurea grown in Taiwan. Food Chem. 2011, 125, 226-231. [CrossRef]

9. Bahri, M.; Hance, P.; Grec, S.; Quillet, M.C.; Trotin, F.; Hilbert, J.L.; Hendriks, T. A "novel" protocol for the analysis of hydroxycinnamic acids in leaf tissue of chicory (Cichorium intybus L., Asteraceae). Sci. World J. 2012, 2012, 142983. [CrossRef]

10. Papetti, A.; Daglia, M.; Aceti, C.; Sordelli, B.; Spini, V.; Carazzone, C.; Gazzani, G. Hydroxycinnamic acid derivatives occurring in Cichorium endivia vegetables. J. Pharm. Biomed. Anal. 2008, 48, 472-476. [CrossRef]

11. Stojakowska, A.; Malarz, J.; Szewczyk, A.; Kisiel, W. Caffeic acid derivatives from a hairy root culture of Lactuca virosa. Acta Physiol. Plant. 2012, 34, 291-298. [CrossRef]

12. Takenaka, M.; Yan, X.; Ono, H.; Yoshida, M.; Nagata, T.; Nakanishi, T. Caffeic acid derivatives in the roots of yacon (Smallanthus sonchifolius). J. Agric. Food Chem. 2003, 51, 793-796. [CrossRef] [PubMed]

13. Silva, T.; Oliveira, C.; Borges, F. Caffeic acid derivatives, analogs and applications: A patent review (2009-2013). Expert Opin. Ther. Pat. 2014, 24, 1257-1270. [CrossRef]

14. Deng, Q.; Penner, M.H.; Zhao, Y. Chemical composition of dietary fiber and polyphenols of five different varieties of wine grape pomace skins. Food Res. Int. 2011, 44, 2712-2720. [CrossRef]

15. Cortés, A.; Moreira, M.T.; Feijoo, G. Integrated evaluation of wine lees valorization to produce value-added products. Waste Manag. 2019, 95, 70-77. [CrossRef]

16. De Bona, G.S.; Adrian, M.; Negrel, J.; Chiltz, A.; Klinguer, A.; Poinssot, B.; Héloir, M.C.; Angelini, E.; Vincenzi, S.; Bertazzon, N. Dual mode of action of grape cane extracts against Botrytis cinerea. J. Agric. Food Chem. 2019, 67, 5512-5520. [CrossRef]

17. Wang, Y.; He, Y.N.; He, L.; He, F.; Chen, W.; Duan, C.Q.; Wang, J. Changes in global aroma profiles of cabernet sauvignon in response to cluster thinning. Food Res. Int. 2019, 122, 56-65. [CrossRef]

18. Fanzone, M.; Zamora, F.; Jofré, V.; Assof, M.; Peña-Neira, Á. Phenolic composition of Malbec grape skins and seeds from Valle de Uco (Mendoza, Argentina) during ripening. effect of cluster thinning. J. Agric. Food Chem. 2011, 59, 6120-6136. [CrossRef] [PubMed]

19. Gil, M.; Esteruelas, M.; González, E.; Kontoudakis, N.; Jiménez, J.; Fort, F.; Canals, J.M.; Hermosín-Gutiérrez, I.; Zamora, F. Effect of two different treatments for reducing grape yield in Vitis vinifera cv Syrah on wine composition and quality: Berry thinning versus cluster thinning. J. Agric. Food Chem. 2013, 61, 4968-4978. [CrossRef]

20. The Commission of the European Communities. Regulation (EU) No 1306/2013 2013, L 347, 671-854. Available online: https: / / eur-lex.europa.eu/legal-content/EN/LSU/?uri=celex:32013R1306 (accessed on 3 February 2021).

21. Salah Eddine, N.; Tlais, S.; Alkhatib, A.; Hamdan, R. Effect of four grape varieties on the physicochemical and sensory properties of unripe grape verjuice. Int. J. Food Sci. 2020, 2020, 1-7. [CrossRef]

22. Dupas de Matos, A.; Magli, M.; Marangon, M.; Curioni, A.; Pasini, G.; Vincenzi, S. Use of verjuice as an acidic salad seasoning ingredient: Evaluation by consumers' liking and Check-All-That-Apply. Eur. Food Res. Technol. 2018, 244, 2117-2125. [CrossRef]

23. Nasser, M.; Cheikh-Ali, H.; Hijazi, A.; Merah, O.; Al-Rekaby, A.E.A.N.; Awada, R. Phytochemical profile, antioxidant and antitumor activities of green grape juice. Processes 2020, 8, 507. [CrossRef]

24. Fia, G.; Bucalossi, G.; Gori, C.; Borghini, F.; Zanoni, B. Recovery of bioactive compounds from unripe red grapes (cv. Sangiovese) through a green extraction. Foods 2020, 9, 566. [CrossRef] [PubMed]

25. Honisch, C.; Osto, A.; Dupas de Matos, A.; Vincenzi, S.; Ruzza, P. Isolation of a tyrosinase inhibitor from unripe grapes juice: A spectrophotometric study. Food Chem. 2020, 305, 125506. [CrossRef] [PubMed]

26. Burin, V.M.; Ferreira-Lima, N.E.; Panceri, C.P.; Bordignon-Luiz, M.T. Bioactive compounds and antioxidant activity of Vitis vinifera and Vitis labrusca grapes: Evaluation of different extraction methods. Microchem. J. 2014, 114, 155-163. [CrossRef]

27. Conde, C.; Silva, P.; Fontes, N.; Dias, A.C.P.; Tavares, R.M.; Sousa, M.J.; Agasse, A.; Delrot, S.; Gerós, H. Biochemical changes throughout grape berry development and fruit and wine quality. Food 2007, 1, 1-22.

28. Wu, C.H.; Murthy, H.N.; Hahn, E.J.; Paek, K.Y. Large-scale cultivation of adventitious roots of Echinacea purpurea in airlift bioreactors for the production of chichoric acid, chlorogenic acid and caftaric acid. Biotechnol. Lett. 2007, 29, 1179-1182. [CrossRef]

29. Wu, C.H.; Murthy, H.N.; Hahn, E.J.; Paek, K.Y. Enhanced production of caftaric acid, chlorogenic acid and cichoric acid in suspension cultures of Echinacea purpurea by the manipulation of incubation temperature and photoperiod. Biochem. Eng. J. 2007, 36, 301-303. [CrossRef]

30. Peng, Y. The Method for Preparing Chicoric Acid from Echinacea purpurea. CN1587251A, 2 March 2005.

31. Chen, B.; Guo, J.; Xie, J. Method for Purifying Chicoric Acid and Monocaffeyltartaric Acid from Echinacea purpurea Extract. CN20081143072, 9 October 2008.

32. Koriem, K.M.M. Caftaric acid: An overview on its structure, daily consumption, bioavailability and pharmacological effects. Biointerface Res. Appl. Chem. 2020, 10, 5616-5623.

33. Sun, R.Z.; Cheng, G.; Li, Q.; He, Y.N.; Wang, Y.; Lan, Y.B.; Li, S.Y.; Zhu, Y.R.; Song, W.F.; Zhang, X.; et al. Light-induced variation in phenolic compounds in cabernet sauvignon grapes (Vitis vinifera L.) involves extensive transcriptome reprogramming of biosynthetic enzymes, transcription factors, and phytohormonal regulators. Front. Plant. Sci. 2017, 8, 1-18. [CrossRef] 
34. Coelho, J.; Barros, L.; Dias, M.I.; Finimundy, T.C.; Amaral, J.S.; Alves, M.J.; Calhelha, R.C.; Santos, P.F.; Ferreira, I.C.F.R. Echinacea purpurea (L.) Moench: Chemical characterization and bioactivity of its extracts and fractions. Pharmaceuticals 2020, $13,125$. [CrossRef]

35. Buiarelli, F.; Coccioli, F.; Merolle, M.; Jasionowska, R.; Terracciano, A. Identification of hydroxycinnamic acid-tartaric acid esters in wine by HPLC-tandem mass spectrometry. Food Chem. 2010, 123, 827-833. [CrossRef]

36. Pour Nikfardjam, M.S. General and polyphenolic composition of unripe grape juice (verjus/verjuice) from various producers. Mitteilungen Klosterneubg. 2008, 58, 28-31.

37. Mulero, J.; Pardo, F.; Zafrilla, P. Antioxidant activity and phenolic composition of organic and conventional grapes and wines. J. Food Compos. Anal. 2010, 23, 569-574. [CrossRef]

38. Kammerer, D.; Claus, A.; Carle, R.; Schieber, A. Polyphenol screening of pomace from red and white grape varieties (Vitis vinifera L.) by HPLC-DAD-MS/MS. J. Agric. Food Chem. 2004, 52, 4360-4367. [CrossRef]

39. Lamuela-Raventós, R.M.; Waterhouse, A.L. A Direct HPLC separation of wine phenolics. Am. J. Enol. Vitic. 1994, 45, 1-5.

40. Ignat, I.; Volf, I.; Popa, V.I. A critical review of methods for characterisation of polyphenolic compounds in fruits and vegetables. Food Chem. 2011, 126, 1821-1835. [CrossRef] [PubMed]

41. Maier, T.; Sanzenbacher, S.; Kammerer, D.R.; Berardini, N.; Conrad, J.; Beifuss, U.; Carle, R.; Schieber, A. Isolation of hydroxycinnamoyltartaric acids from grape pomace by high-speed counter-current chromatography. J. Chromatogr. A 2006, 1128, 61-67. [CrossRef]

42. Pritchard, J.K.; Stephens, M.; Donnelly, P. Inference of population structure using multilocus genotype data. Genetics 2000, 155, 945-959. [PubMed] 